\title{
In-situ experiments for the determination of rock properties and behaviour at the Meuse/Haute Marne Centre
}

\author{
J. Morel ${ }^{1, a}$, J. Delay ${ }^{1}$, G. Armand ${ }^{1}$, H. Rebours ${ }^{1}$, and N. Conil ${ }^{1}$ \\ ${ }^{1}$ Andra, Centre de Meuse/Haute Marne, RD 960, 55290 Bure, France
}

\begin{abstract}
Andra is in charge of studying the feasibility of a disposal facility for longlived high-level nuclear waste (LL-HLW) in a deep geological environment. With this aim, dedicated experiments have been carried out for several years at the Meuse/Haute Marne Underground Research Laboratory excavated in a $500 \mathrm{~m}$ deep argillaceous rock formation. These experiments include determining the feasibility of the excavation of disposal cells for LL-HLW, consisting of 40 meter long, $70 \mathrm{~cm}$ in diameter, horizontal cased micro tunnels. The hydro mechanical impact of the excavation of such openings on the rock mass behaviour is continuously monitored as well as their mean term mechanical behaviour. Since LL-HLW produce heat, the impact of temperature on the surrounding rock mass and on the micro tunnel steel casing will also be studied. Specific instrumentation has been developed to study this impact. The first step of the microtunnel excavation tests, carried out in 2009 , has led to improving the excavation method and the drilling machine. These improvements will be tested in the next step of the excavation tests planned for 2010. The THM experiment dedicated to studying the behaviour of the rock mass under thermal solicitation started early 2010. The behaviour of a steel casing in contact with the rock mass and under thermal solicitation will be studied in an experiment scheduled to start in September 2010.
\end{abstract}

\section{Introduction}

\subsection{General context}

Andra, the French national radioactive waste management agency, is in charge of studying the feasibility of a disposal facility for long-lived high-level waste (LL-HLW) in a deep geological environment. With this aim, the excavation of the Meuse/Haute Marne Underground Research Laboratory (URL) has been excavated since 2000 in a deep argillaceous rock formation (CallovoOxfordian) in order to carry out experiments [1]. The subjects of these experiments are either strictly scientific (understand the thermo-hydro-mechanical properties of the rock, their chemical interactions, etc.), or cover technological aspects (verify the feasibility of the excavation of openings intended for waste disposal, and study their behaviour). In order to achieve the desired objectives, a specific methodology has been implemented to design each experiment and its instrumentation, and

\footnotetext{
a e-mail : jacques.morel@andra.fr
} 
to choose its location and the most effective installation procedure. The design process also relies on numerical modeling.

The main objective of the research is to characterize the confining properties of the argillaceous rock formation through in-situ hydro geological tests, chemical measurements and diffusion experiments, and to demonstrate that the construction and operation of a geological disposal will not introduce pathways for radionuclides migration.

The design of disposal cells studied for high level waste consists of 40 meter long, $70 \mathrm{~cm}$ in diameter horizontal micro-tunnels. To prevent against rock deformation, the micro-tunnel is lined with a casing allowing the retrieval of waste canisters. Cells are finally sealed with a swelling clay plug, itself confined with a concrete plug (Figure 1).

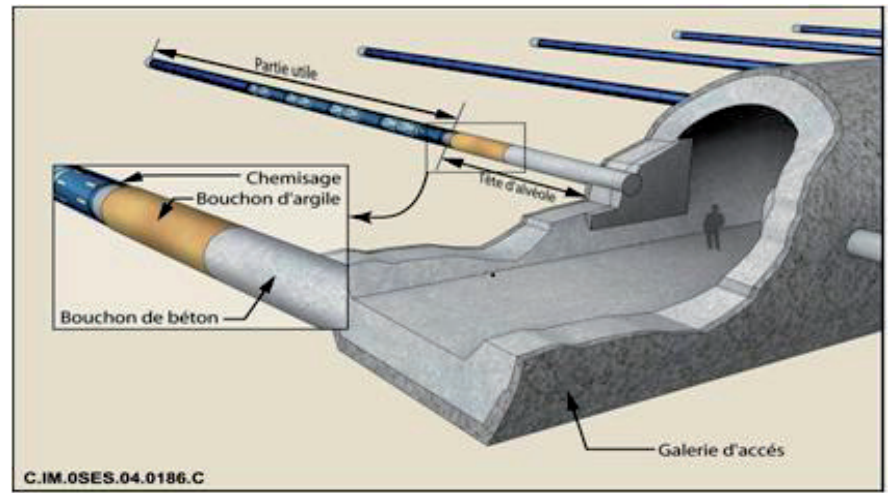

Fig. 1: Concept of disposal cells for high level activity wastes.

One of the objectives of the technical and scientific program carried out in the URL is to verify the feasibility of the excavation of such micro-tunnels in the $500 \mathrm{~m}$ deep argillaceous rock formation, and to study the thermo-hydro-mechanical behaviour of such disposal cells and the surrounding rock mass. With this aim, specific experiments have been developed to study:

- the hydro mechanical response of the argillaceous rock to the excavation,

- the mechanical behaviour of the micro-tunnel after excavation,

- the behaviour of the steel casing under rock deformation and thermal solicitation,

- the hydro mechanical response of the argillaceous rock to a thermal solicitation.

\subsection{Geological and geomechanical context}

The target horizon for the URL is a 135 meter thick layer of argillaceous rock lying between about 420 and 555 meters below the surface. From a stratigraphic viewpoint (Andra 2005), the depositional period straddles the middle Callovian and early Oxfordian subdivisions of the middle to upper Jurassic. Argillaceous rocks contain a mixture of clay minerals and clay-sized fractions of other compositions. The clay minerals, which constitute on average $40 \%$ to $45 \%$ of the CallovoOxfordian argillaceous rocks, ensure groundwater tightness and radionuclides retention. Silica-rich and carbonate-rich sedimentary components contribute to the high stiffness of the rock and to the stability of the underground construction. The Callovo-Oxfordian clays are overlain and underlain by poorly permeable limy formations.

Table 1 gives the Callovo-Oxfordian (COX) mechanical characteristics. Sedimentation has led to a slightly anisotropic behaviour of the argillites (not taken into account in Table 1). In situ measurements indicate a strong coupling between the mechanical and hydraulic processes [2]. Small deformations imply an increase or a drop in pore pressure.

Wileveau et al. [3] have demonstrated the anisotropy of the stress state; the major stress $\sigma_{1}$ is

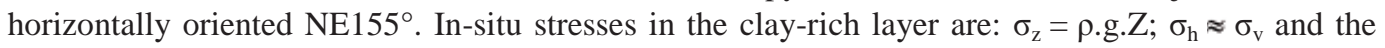


ratio $\sigma_{\mathrm{H}} / \sigma_{\mathrm{h}}$ is close to 1.3 , with magnitude varying with depth and with the rheological characteristics of the respective layers.

Table 1. COX characteristics

\begin{tabular}{|c|c|c|}
\hline Rock parameter & Notation & Value \\
\hline Density & $\rho$ & $2.39 \mathrm{~g} / \mathrm{cm}^{3}$ \\
\hline Porosity & $\mathrm{N}$ & $7.2 \pm 1,4 \%$ \\
\hline Intrinsic permeab. & $\mathrm{k}$ & $5 \times 10^{-20} \mathrm{~m}^{2}$ \\
\hline Water content & $\mathrm{W}$ & $7.2 \pm 1,4 \%$ \\
\hline Young modulus & $\mathrm{E}$ & $4000 \pm 1470$ \\
$\mathrm{MPa}$
\end{tabular}

\section{Description of the experimentations}

\subsection{Micro-tunnel excavation tests}

Excavation tests of micro-tunnels are performed using a guided auger drilling machine. Prior to the excavation, pore pressure measurement devices are installed in standard diameter boreholes at different distances from the theoretical trajectory of the micro-tunnels, in order to monitor the hydromechanical impact of the excavation on the rock mass behaviour (Figure 2). Both pore pressure and temperature are measured in $20 \mathrm{~cm}$ long test intervals ( 3 to 5 test intervals per borehole) saturated with water and isolated from the rest of the borehole with sealed packers. The devices are installed several weeks before the excavation of the micro-tunnels to give enough time to the pressure in the test interval to reach the rock mass pore pressure.

After excavation, a 3D scan and video inspection have been carried out in one of the tunnels, with equipment specially designed for this purpose, to obtain a qualitative characterization of the micro-tunnel: trajectory, geometry and quality of the excavation, casing alignment.

Convergence measurements were then carried out in the micro-tunnel to investigate its meanterm deformation behaviour (Figure 3). The device used for this purpose consists of several instrumented sections mounted on wheels, pushed inside the micro-tunnel to the target measurement location. Each section allows the measurement of displacement along 4 diameters by the means of potentiometers. Once installed at the desired location, the sensors are put in contact with the micro- 
tunnel wall using pneumatic jacks. Each section is also equipped with a temperature and relative humidity sensor to monitor the potential impact of atmospheric conditions in the micro-tunnel on the deformation behaviour.

All sensors are connected to a centralized acquisition and management data system (SAGD).

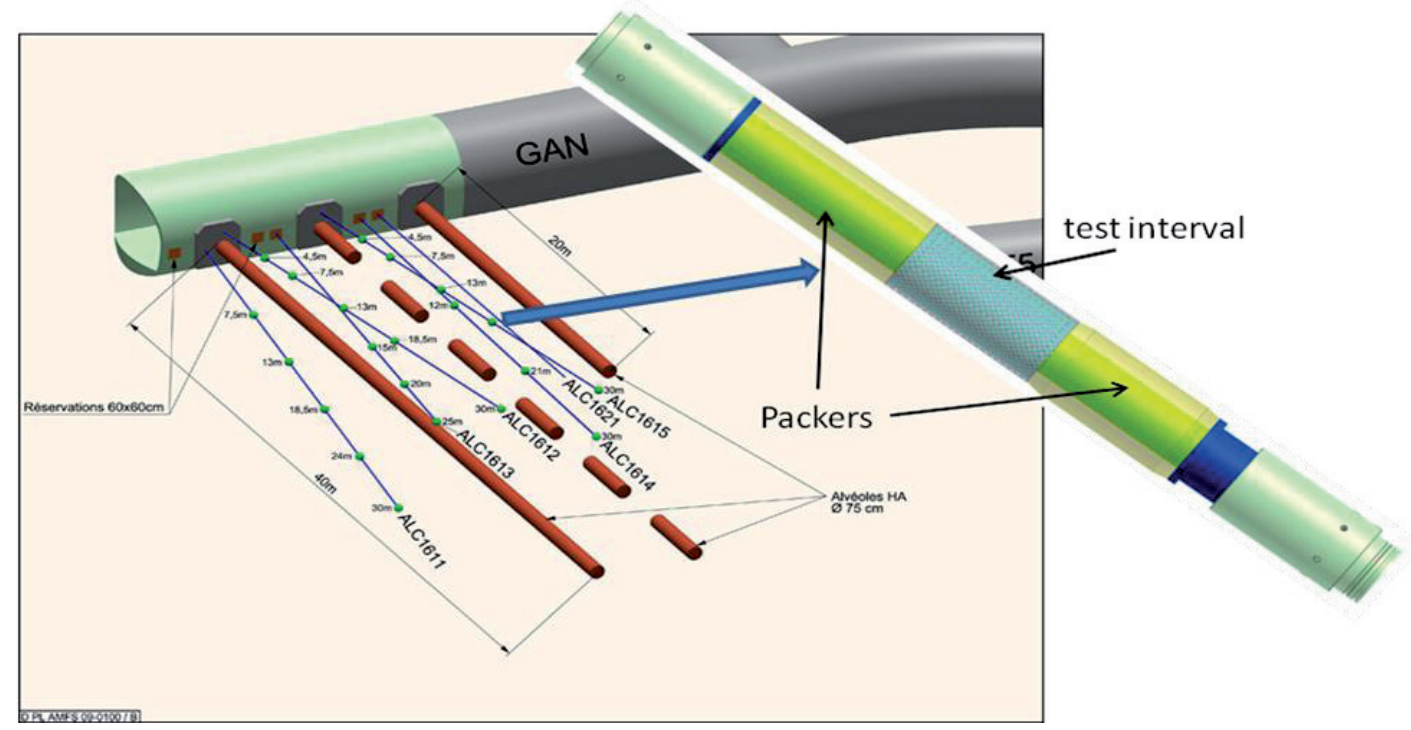

Fig. 2: Pore pressure measurements boreholes, with the specific system (PP) developed by Solexperts [4]

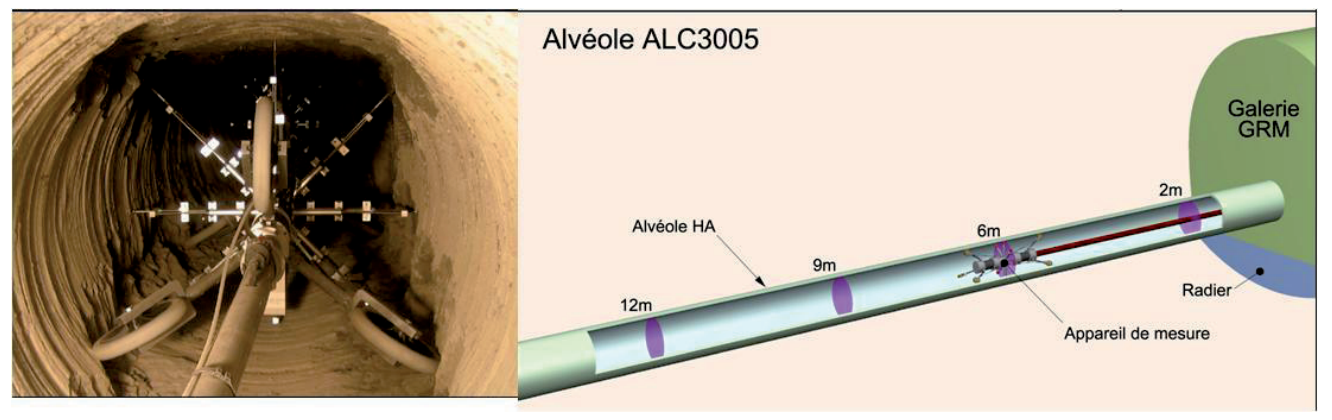

Fig. 3: Convergence measurements in the micro-tunnel, with the device developed by Egis Géotechnique

3D numerical modeling of the micro-tunnels has been carried out to predict the hydromechanical and visco-plastic behaviour of the rock mass with the view to assisting in the choice of the measurements location [5].

\subsection{Mechanical behaviour of the micro-tunnel steel casing}

Since high level activity wastes produce heat, micro-tunnel casing deformation is induced not only by rock deformation (convergence of micro-tunnel wall) but mainly by thermal solicitation (casing dilatation). Dilatation of the steel casing in contact with the micro-tunnel wall might induce thermomechanical stresses in the steel casing. In order to quantify these phenomena, a specific instrumentation has been designed consisting of an instrumented $140 \mathrm{~mm}$ diameter steel tube (strain gauges, displacement and temperature sensors) installed in a $10 \mathrm{~m} \mathrm{long}, 146 \mathrm{~mm}$ in diameter 
borehole, in which a heater is put in place. The contact between the tube and the borehole wall is ensured by convergence.

Local deformation of the steel tube, in the axial and orthoradial directions, will be measured on 3 sections with strain gauges. Witness gauges will be used for the compensation of temperature effect. Deformation in the radial direction will be measured with inductive sensors on one diameter for each section. Global dilatation of the steel tube will be measured using a 4-point extensometer. The anchors will be fixed to the tube at different depths, the invar rods will pass in the middle of the heater along the axis of the tube.

Several heating phases will be carried out at temperatures of up to $90^{\circ} \mathrm{C}$, and the deformation of the tube in contact with the borehole wall will be continuously monitored on the SAGD data acquisition system.

For technical reasons, due to trajectory precision when drilling a borehole, the behaviour of the rock mass in the immediate vicinity of the steel tube cannot be investigated. However, additional peripheral boreholes, drilled at a few tenths of centimeters from the cased borehole, will be instrumented to monitor the temperature, interstitial pressure and rock deformation around the cased borehole. These measurements, together with the results of previous numerical modeling and experimental results, will help to estimate the conditions occurring at the rock mass/steel tube contact.

\subsection{Rock mass hydro-mechanical response to thermal solicitation}

A dedicated Thermo-Hydro-Mechanical (THM) experiment has been designed to measure the impact of heating on the hydro mechanical response of the host rock. It consists of three 16 meter long, $160 \mathrm{~mm}$ in diameter boreholes, each equipped with a heater probe arranged according to a design (diameter, length, distance to each other) taking into account at a smaller scale the one intended for the disposal cells (Figure 4). To avoid the THM influence of the access drift, heating will only be applied between 12 and $16 \mathrm{~m}$ depth. Several heating phases will be conducted at temperatures of up to $90^{\circ} \mathrm{C}$.

Peripheral boreholes have been instrumented to monitor the temperature (9 boreholes, 90 single and duplex Pt100 sensors), pore pressure (12 boreholes, with single and multi-intervals devices, 18 measurement points) and deformation (3 boreholes, for manual extensometers and inclinometers) in the host rock around the heated boreholes.

All sensors are connected to the SAGD.

Numerical modeling has been carried out to predict the thermo-hydro-mechanical behaviour of the rock mass, with the view to assisting in the choice of the measurements location.

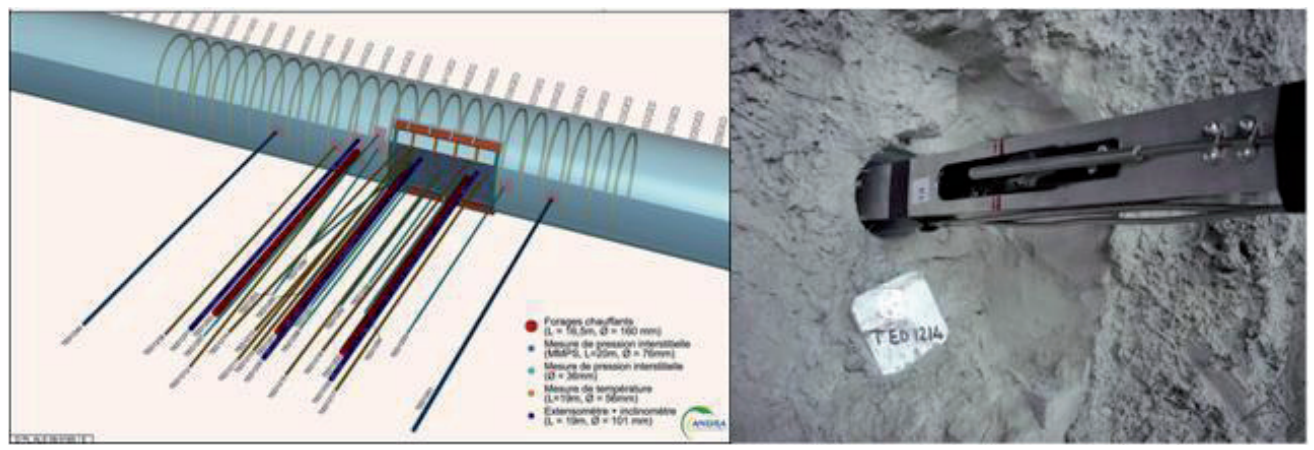

Fig. 4: Design of the THM experiment, and detail of a probe for temperature measurement in a peripheral borehole (Pt100 duplex, probe designed by Aitemin) 


\section{Preliminary results}

\subsection{Hydro-mechanical response to micro-tunnel excavation}

The first phase of the micro-tunnel excavation test program was carried out in 2009 [6]. Three 10 to $20 \mathrm{~m}$ long micro-tunnels were excavated in 2 directions with respect to the stress state orientation. The excavation of a $20 \mathrm{~m}$ long micro-tunnel took about 3 days.

The pore pressure recorded during and immediately after the excavation of the micro-tunnels shows important overpressures generated by the excavation. Figure 5 shows, for example, overpressures induced in the horizontal plane of a micro-tunnel oriented along the major stress direction. Overpressure reaches 35 bars at a distance of $0.9 \mathrm{~m}$ from the micro-tunnel wall, 18 hours after excavation, and propagates in the argillaceous rock. The overpressure peak, with a value of 20 bars, is reached at a distance of $1.8 \mathrm{~m}$ from the micro-tunnel wall, 21 days after excavation. In some cases, these overpressures are significantly higher than those predicted by modeling. This suggests the influence of parameters that were not taken into account in the modeling, such as the pressure of the drilling machine on the excavation front, or the temperature increase induced by drilling (the micro-tunnel is not ventilated during excavation).

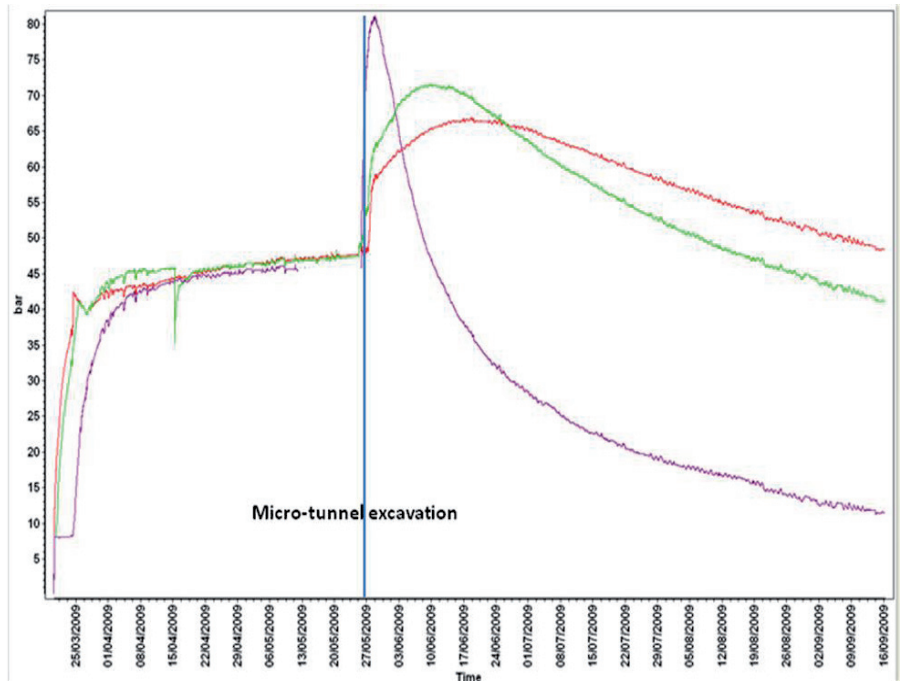

Fig. 5: Influence of micro-tunnel excavation on rock mass interstitial pressure. Measurements points at $0.9,1.4$ and $1.8 \mathrm{~m}$ from the micro-tunnel wall

\subsection{Mechanical behaviour of the micro-tunnel}

The final geometry of the micro-tunnel shows difference with the theoretical $74 \mathrm{~cm}$ diameter section. Over-profiles of several centimeters were induced by the formation of an excavation damaged zone (EDZ) around the micro-tunnel and the fall of the damaged rock. The location of breakouts is consistent with the orientation of the stress field (figure 6). 


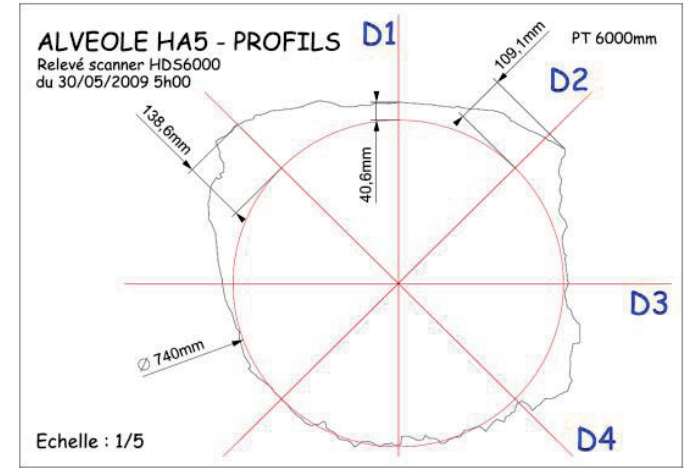

Fig. 6: Typical breakouts observed in a micro-tunnel oriented along the major horizontal stress direction, and subjected to minor horizontal stress $\sigma_{\mathrm{h}} \approx$ vertical stress $\sigma_{\mathrm{v}}$

Due to these over-profiles, about $20 \%$ of the convergence sensors could not be put in contact with the micro-tunnel wall. The main part of the convergence occurred in the first months $(0.5$ to $2 \%$ in the first 3 month). Subsequently, convergence was mainly driven by creep at a much slower rate (less than $0.1 \%$ per month).

\subsection{Behaviour of the rock mass and of the steel casing to thermal solicitation}

The heating phase of the THM experimentation started end of January 2010, with a first heating phase at $45^{\circ} \mathrm{C}$ in the central borehole. All sensors, except 4 temperature sensors, are functioning properly. Figure 7 shows the temperature increase since the beginning of the heating phase in a peripheral borehole located at a distance of $60 \mathrm{~cm}$ from the heater borehole. A second phase will be initiated after 4 months, and a third phase at $90^{\circ} \mathrm{C}$, again 4 months later. The other two heaters will be activated 1 year after the beginning of the first phase.

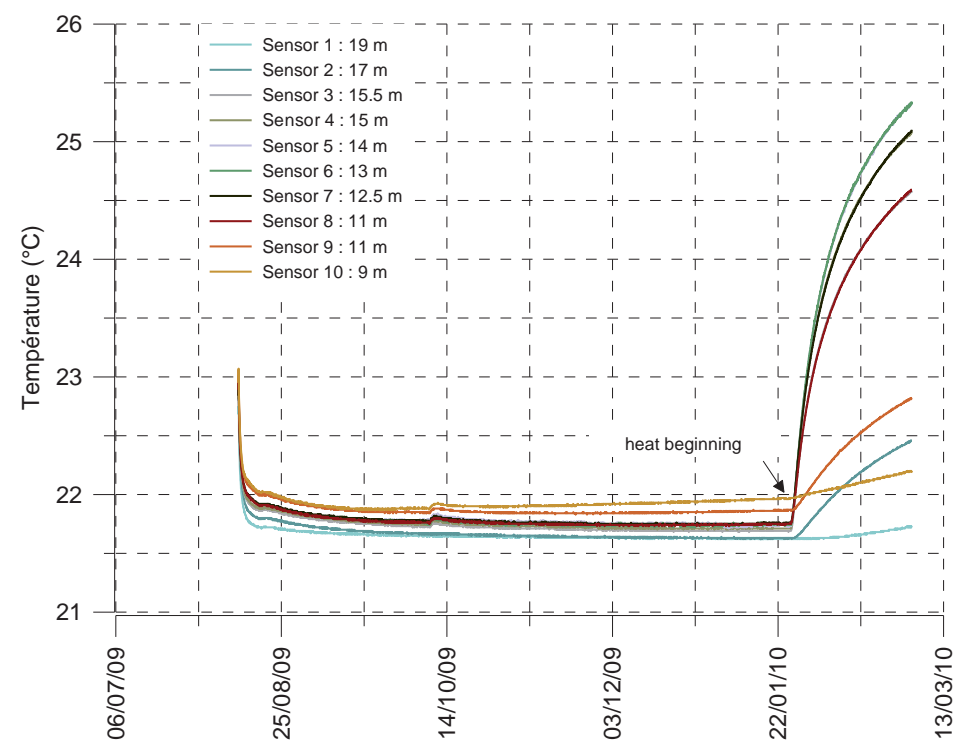

Fig. 7: THM experiment - temperature in a peripheral borehole 


\section{Conclusion}

A technical and scientific program has been designed to test, in a $500 \mathrm{~m}$ deep clay-stone formation, the feasibility and behaviour of horizontal micro-tunnels intended for a LL-HLW waste disposal. Specific experiments are underway to study the thermo-hydro-mechanical behaviour of such openings and of the surrounding rock mass.

Excavation tests of the micro-tunnels show over-profiles induced by the damaging of the rock mass during excavation, and the hydro-mechanical impact of the excavation on the surrounding rock mass, in some cases much stronger than predicted by the numerical modeling. These results show the need to improve the excavation method and machine, in order to optimize the quality of the excavation and be able to build a $40 \mathrm{~m}$ long cased micro-tunnel. These improvements (modification of the drilling head, minimization of the vibrations, optimization of the guidance instructions, etc.) will be implemented in the next test campaign scheduled for April 2010. The impact of the temperature generated by the drilling machine on the hydro-mechanical response of the host rock will also be studied.

The THM experiment, dedicated to studying the behaviour of the rock mass under thermal solicitation, has been successfully installed. Heating has been running since January 2010 and will run for several years.

The behaviour of the steel casing under thermal solicitation will be studied in an experimentation scheduled for September 2010.

\section{References}

1. J. Delay, A. Vinsot, J.M. Krieguer, H. Rebours, G. Armand, Phys. Chem. Earth 32 (2007)

2. G. Armand, M. Souley, K. Su, V. Renaud, Y. Wileveau, Proceedings of Sea to Sky Geotechnique, Vancouver, Canada ( 2006)

3. Y. Wileveau, F.H. Cornet, J. Desroches, P. Blümling, Phys. Chem. Earth 32 (2007)

4. T. Fierz, M. Piedevache, J. Delay, G. Armand, J. Morel, FMGM : Seventh International Symposium on Field Measurements in Geomechanics (2007)

5. V. Renaud, J. Morel, Journées Nationales de Géotechnique et de Géologie de l'Ingénieur, Grenoble, France (2010)

6. J. Morel, V. Renaud, G. Armand, Rock Engineering in Difficult Ground Conditions - Soft Rocks and Karst - Vrkljan ed. (2010) 